\title{
Coding of Nociceptive Signals: Role of Slow Sodium Channels
}

\section{B. V. Krylov}

Pavlov Institute of Physiology, Russian Academy of Sciences, nab. Makarova, 6, St. Petersburg, 199034 Russia; e-mail: krylov@infran.ru

DOI: $10.1134 / \mathrm{S} 1990747809030295$

Now it is widely accepted that slow sodium channels $\left(\mathrm{TTX}_{\mathrm{r}}, \mathrm{Na}_{\mathrm{v}} 1.8\right)$ play a crucial role in regulating the properties of nociceptive neurons and, consequently, nociceptive behavior. We report here that voltage sensitivity of these channels (resulting in the changes of effective charge transfer of their activation gating system) is under the control of newly found opioid-like receptors. It is well known that opioids act via receptors associated with G-proteins. Our data led to the hypothesis that there is an interaction between new opioid-like receptors, $\mathrm{Na}^{+}, \mathrm{K}^{+}$-ATPase (G-proteins are not involved in this mechanism as signal transducers), and the activation gate of $\mathrm{Na}_{\mathrm{v}} 1.8$ channels. We demonstrate that comenic acid is a potent and highly selective modulator of this signaling system due to its ligand-receptor interaction with opioid-like receptor. The pre-clinic tests of comenic acid as a pharmacological substance of the new non-opioid analgesic demonstrate a significant pain relief after nerve injury and inflammation. The analgesic has an important advantage that results in the absence of negative side effects. 